\title{
Web System for Online and Onsite Usage of Geoinformation by Surveying Sector in Kosovo. Case Study: Ferizaj Municipality
}

\author{
Bashkim Idrizi, Mirdon Kurteshi \\ Department of Geodesy, University of Prishtina "Hasan Prishtina" \\ Str. "George Bush", no.31, 10000 Prishtinë, Kosovo \\ bashkim.idrizi@uni-pr.edu, mirdoni@hotmail.com
}

Received 18 August 2019/ Revised 29 October 2019/ Accepted 1 November 2019/ Published 1 December 2019/

Available Online 25 November 2019

\begin{abstract}
The purpose of research to determine and contribute in more efficient services to geoinformation stakeholders, as well as to give positive impact on increasing income in geo business sector, voluntary based web system for online usage of geoinformation in Kosovo has been developed. The method used was puting in to one place many sourcec via WMS and WFS services, by creating thematic SDI, in order to have online system with dynamic data comming from official databases with update from last day on $5 \mathrm{pm}$. System is open for usage by all interested parts, however official registration is required. It contains geoinformation from many databases such as cadastral, orthophoto, municipal, and basemaps from open layers. The results show that the system is extendable and it is permanently including new datasets based on the user requirements. All available data is linked via web services, which gives an opportunity to users to use the updated version of datasets as they are published by responsible institution via www (world wide web).
\end{abstract}

Keywords: web map, geoportal, geoinformation, web services, Kosovo

\section{Introduction}

In this era Web has changed every aspect of our life from our daily activities to our profession's activities like our jobs and so on. Among these changes, GIS has been affected by this technology and a new technology, which is called Web GIS, appeared. Today, a vast majority of Internet users uses this technology but most of them don't notice it. Web GIS originates from a combination of web technology and the Geographical Information System, which is a recognized technology that is mainly composed of data handling tools for storage, recovery, management and analysis of spatial data Web GIS is a kind of distributed information system.

Web services are self-contained, self-describing, modular applications that can be published, located, and dynamically invoked across the web (ISO 2001). Web services provide access to sets of operations accessible through one or more standardized interfaces 
(Alameh, 2010). While general web services provide interoperability between systems in different domains, geospatial web services introduce geographic reasoning to the services and go a step further by facilitating cross-institutional interchange of geographic data and services over the internet, and by improving the sharing of geographic resources among a variety of data sources (Davis and Alves, 2007). Web Services give us a means of interoperability between different software applications running on a variety of platforms. Web Services support interoperable machine-to-machine interaction over a network. Every Web Service has an interface described in a machine-readable format (Savar, Pierce and Fox, 2005).

Geospatial web services differ from the regular web services by the presence of geographic data on the input (e.g., a bounding box), or on the output (e. g., a basemap of a city), or even on the type of processing (e. g., verification of whether a street crosses another), or in a combination of them (Davis and Alves, 2007).

Gradual on-going transformation is primarily fueled by the growing role of GIS in today's organizations, the increasing availability of spatial data and its inherent conduciveness to reuse, the relative maturity of web and distributed computing technologies, and the key role of GIS in a promising location-based services market (Alameh, 2010). In order to create architecture for the GIS services, it is necessary to create Web Service correspondences of each GIS services. GIS services can be grouped into three categories: Data services, processing services, and Registry or Catalog services (Sayar, 2008).

Online mapping services from different providers cannot, in most cases, interoperate or communicate with one another. Thus, it is seldom possible for a user to get a hazardous waste map from one Web site and a street map from another site and overlay them in the same composite map (Sahin and Gumusay, 2008). To fully realize the capability and benefits of geographic information and GIS technology, spatial data needs to be shared and systems need to be interoperable (ESRI, 2003). The future of GIS technology depends on the interoperability with Web services. Web services are accessible with browsers, telephones, PDA's and most of the upcoming information devices (Ummadi, 2008).

Performed research presented in this paper is related directly to usage of web-based technology in GI science, with practical example in Ferizaj municipality in the Republic of Kosova. Lack of developed online systems in Kosova for users in geo community was the main driver for performing this research, as well establishing an SDI, and developing platform by including dynamically many official geo databases coming from different sources, as well open layers. Challenge of this research project was to include in one place 
geodata from different SDI levels, i.e. local (municipal), national (geoportal), and global (open layers) SDIs', to provide to geo community a system for online field use with updated data, to increase the awareness for using online systems in practice by all geo stakeholders, to speedup field work in geo sector, as well rational use of web services enabled by WEB GIS technology and contents in geoportal of the Republic of Kosova.

Previous studies related to this research are web-based geoinformation could be a reference in making decisions related to wetland area planning (Siles et al, 2019). General data integration could be done using geospatial analysis (Walter and Sörgel, 2018). Environmental change analysis could be assessed using temporal analysis (Gitis et al, 2016). Human resource development is the most important thing for the success of the quality of geospatial analysis (Mwange et al, 2018). The concept of GI is very useful for the development of geospatial analysis related to spatial patterns (Henzen, 2018).

The above research' results have not reviewed the web system related to online and onsite usage integration, so the current research will be focus on the study of online and onsite usage implementation on geoinformation systems. The purpose of research to determine and contribute in more efficient services to geoinformation stakeholders, as well as to give positive impact on increasing income in geo business sector, voluntary based web system for online usage of geoinformation in Kosovo has been developed.

\section{Methods}

The method of this study based on establishing the SDI, based on another existing SDI's in local, national and global level, by puting in to one place many sourcec via WMS and WFS services. Main objective is to have online system with dynamic data comming from official databases with update from last day on $5 \mathrm{pm}$. This anable to have system without developed own database.

The system was developed by using many software for desktop usage, server usage, database, and programing, as HTML, PHP, JAVASCRIPT, SQL and CSS, while the SQL database for cadastral parcels as encrypted data is used for the system, and shapefiles are converted to KMZ and JSON files in order to be used in system.

System interface is developed to be easy for use by all users, without need for deeper knowledge on WEB GIS and/or SDI, in national Albanian language.

Based on main field activities of geo experts, especially in cadaster, topographic surveying, and urban/spatial planning, aimed to be friendly for users, system was 
methodologically divided in six modules, linked dynamically with external databases, that enable users to find provided products, transform coordinates between different CRSs', find products based on location/coordinates, divide parcels in ideal parts, find roads by attributes and obtain list of spatial coordinates in different coordinate systems.

\section{Results and Discussion}

\subsection{Online and onsite usage of geoinformation}

There is a global set of principles on how to publish data developed by governments, civil society, and data experts. Most government data are inaccessible to the regular citizen, unless someone makes a request. There are justifiable reasons to limit access to certain types of data, for security or data protection purposes, but there is a growing movement across the globe to make data available to the public to make informed decisions and participate in civil discourse. Right management with environment has direct impact on society developing, which also means direct impact on human life.

LBS represents a progressive development from Internet GIS and mobile computing and relies on new information and communication technologies (NICTs) such the latest generation mobile phones using high-level communication protocols (e.g. WAP) and personal digital assistants (PDA) with the ability to be 'location aware' either through the use of embedded GPS or network-based methods. The convergence of the various technologies is illustrated in Figure 2 (Brimicombe, 2002), which shows the technological ability for establishing web system for online and onsite usage of geoinformation.

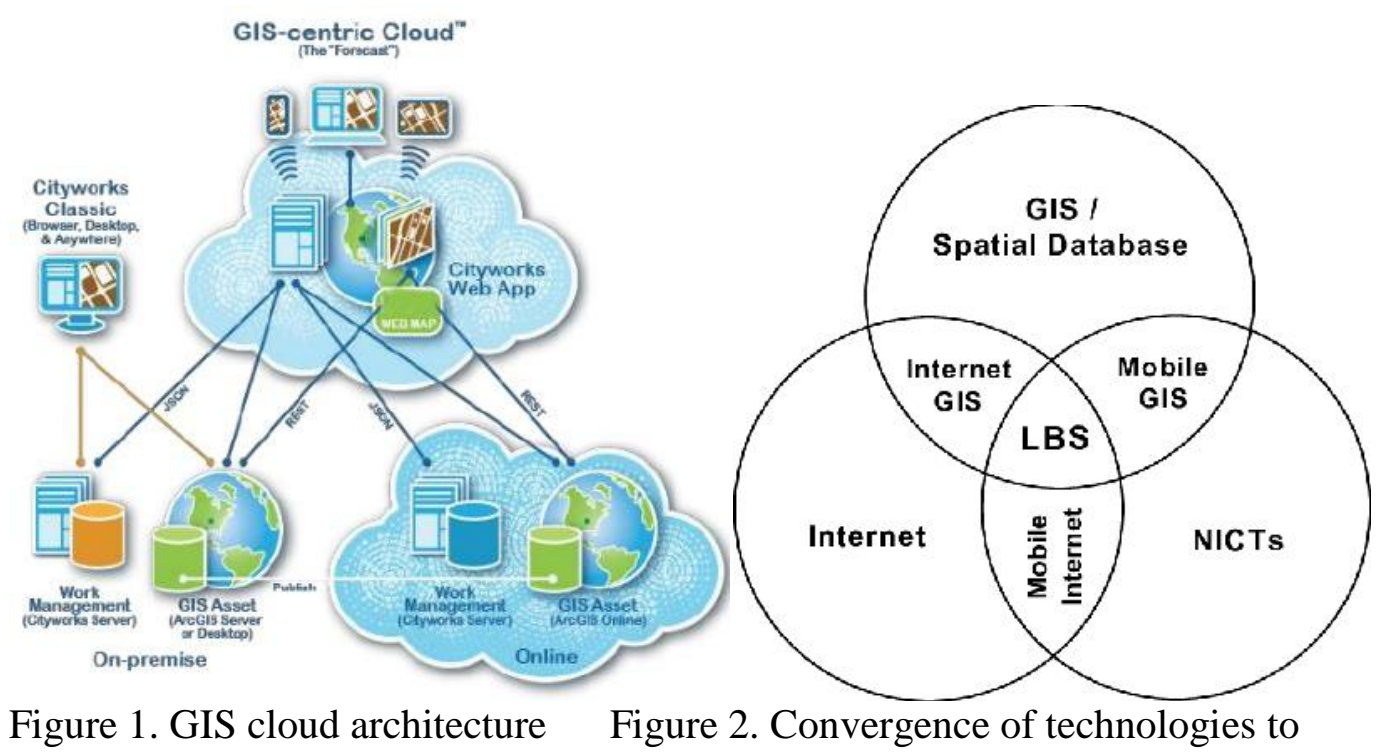

create location based services (LBS) 
(Brimicombe, 2002)

3.2 Available geoinformation datasets in Kosovo useful for surveying sector

The Kosova Cadastral Agency (KCA) is main governmental institution responsible for standardization of spatial data, as well integrating all spatial data in national level within the national geoportal. Under direct responsibility of KCA, national geoportal is established and operational, with a huge number of available spatial datasets such as orthophoto, aerial photography's, topographic maps, cadastral units, administrative units, utilities, cadastral maps, referent networks, address system, road network, railways, hydrology, population, agricultural statistics, protested sites, valuation zones, land cover, geology, climatology, measurements and sizes, and sketches. All above mentioned spatial datasets, are open for usage by stakeholders via WMS (http://geoportal.rks-gov.net/wms), which give opportunity for utilization of all data published in geoportal directly in software/application.

\subsection{Developing web system for online and onsite usage of geoinformation}

The web system for online and onsite usage of geoinofmration by surveying sector in the Republic of Kosova, has been developed based on above mentioned criteria/standards for web GIS and SDI, as well as available datasets via web servers. Objectives of new platform are joint usage of many databases, fast action, decrease cost and time consuming, and simple user interface.

\subsection{Software}

The system development was performed by using/combining many software for desktop usage, server usage, database, and programing. As basic programing platforms were used HTML, PHP (fig.3), JAVASCRIPT, SQL (fig.5) and CSS (fig.4). Bellow some code extracts are given for HTML, PHP [6], CSS, and JAVASCRIPT [9]. 


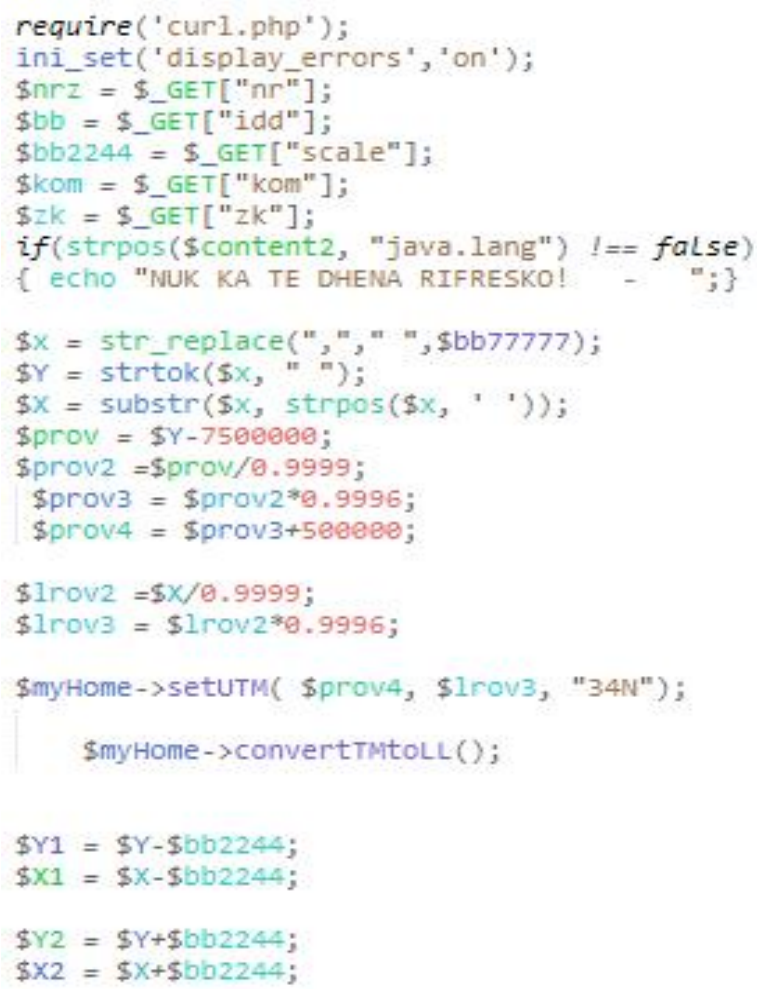

Figure 3. Example of PHP code

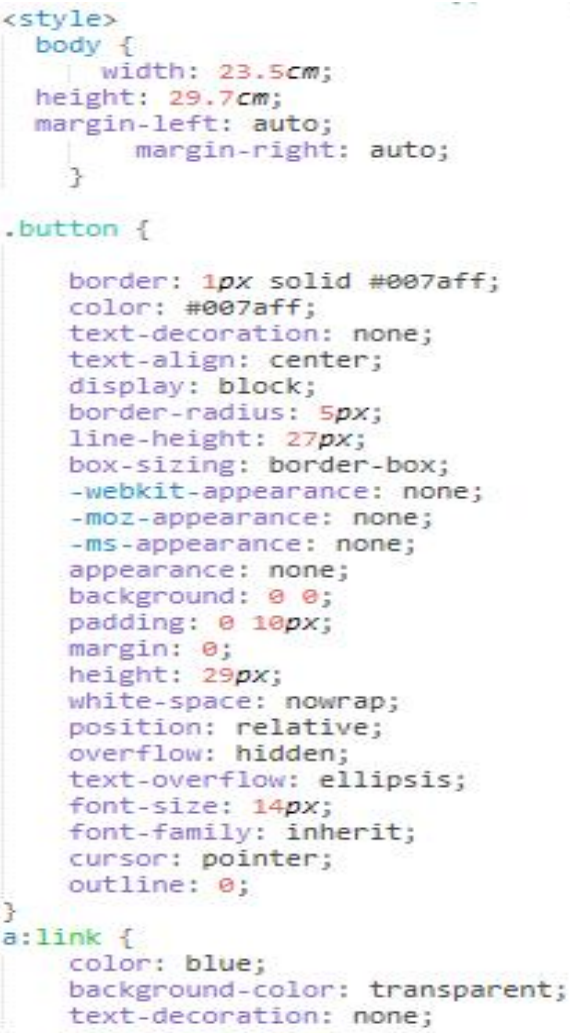

Figure 4. Example of CSS code

SQL database [11] for cadastral parcels as encrypted data is used for the system, while shapefiles are converted to KMZ and JSON files.

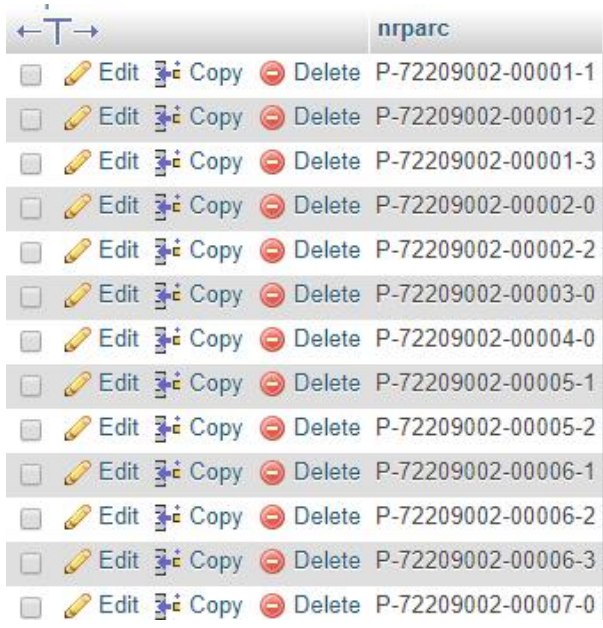

Figure 5. Example of SQL database

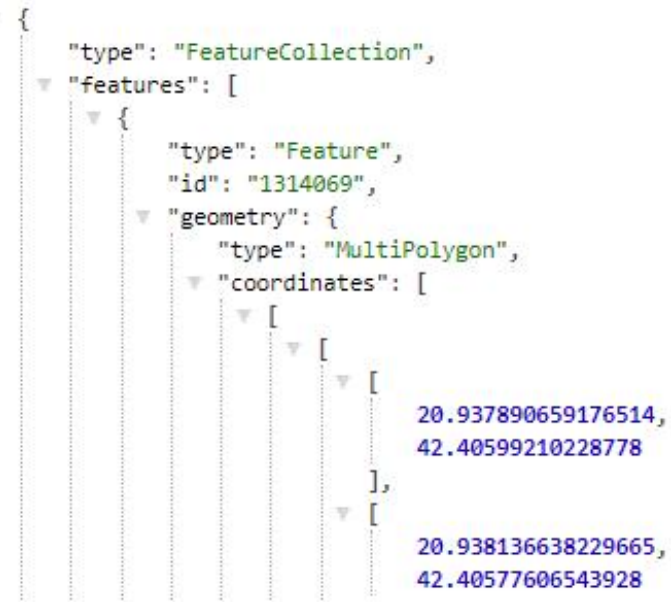

Figure 6. Example of code in KMZ file 


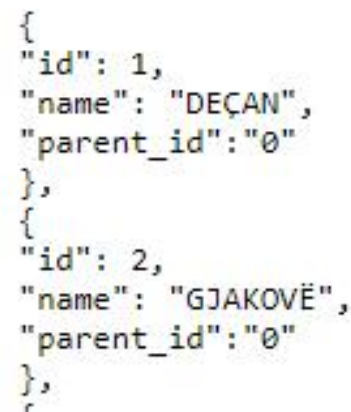

Figure 7. Example of code in JSON file

\subsection{Inputs}

As input data needed for field work of surveyors in performing cadastral measurements, many data sources have been linked within our system, in order to be used together within same SDI. Since cadastral sector require spatial data related to boundaries of land parcels, constructions, infrastructure objects etc., input datasets via web services are as bellow: parcel numbers via KCA geoportal in JSON format (figure 8), parcel number, area, polygon coordinates and coordinate system via WFS of KCA geoportal in XML format parcel number, code of cadastral zone, centroid coordinates, and coordinate system via WFS of KCA geoportal in XML format, cadastral parcels, orthophoto maps, geodetic network points and parcel numbers as image via WMS of KCA geoportal in JPEG, TIFF and/or GEOTIFF formats, geodetic points via WFS of KCA geoportal in JSON format API to google satellite images as open layer via googleapis, attribute data of urban developing plan (for destination of areas, roads in all levels, cadastral zones, forests, agricultural land, and hydrography) via WMS link to the municipal database, attribute data of urban regulatory plan (for buildings line and regulation line) via WMS link to the municipal database (figure 10), and other data via WFS of geoserver in formats GML2 and JSON.

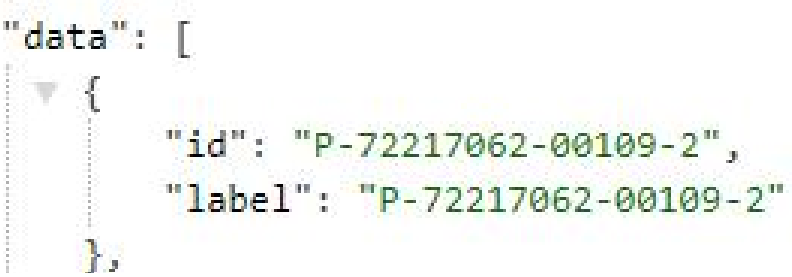

Figure 8. Example of parcel numbers in JSON format 
Bashkim Idrizi and Mirdon Kurteshi / GEOSI Vol 4 No 3 (2019) 230-246

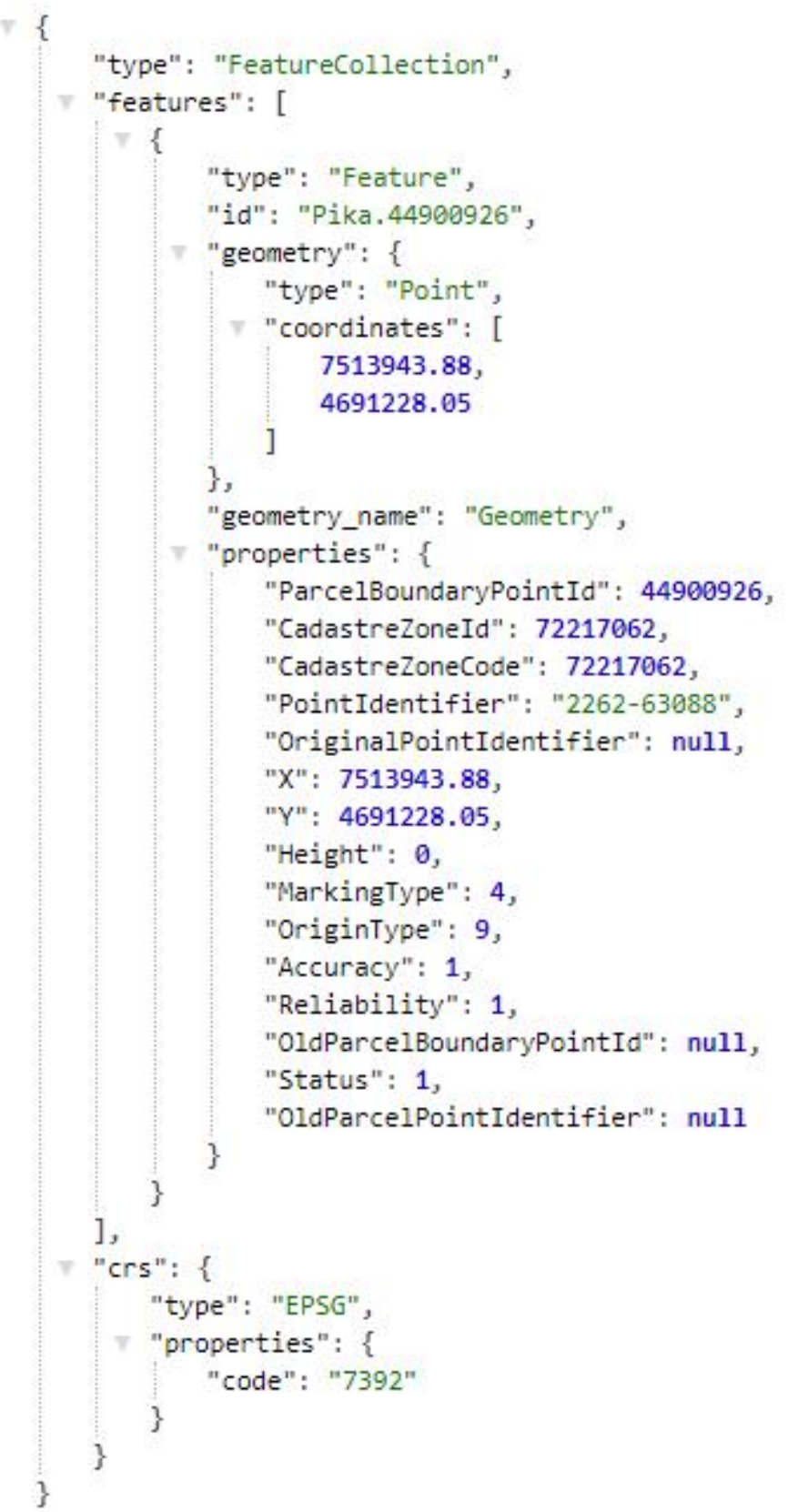

Figure 9. Example of geodetic points in JSON file 


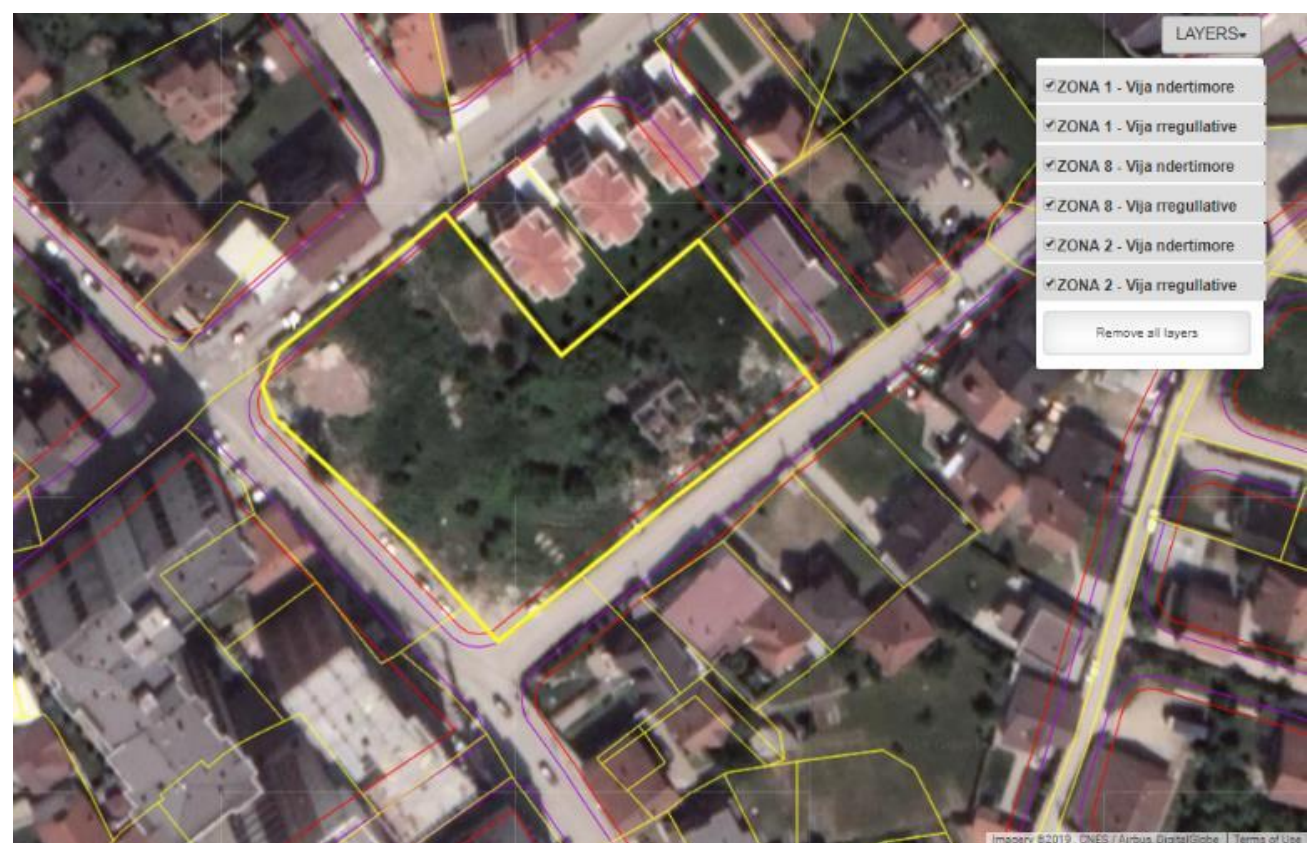

Figure 10. Example of urban regulatory plan

3.6 Functionalities and usage

Developed system is available via direct link in web [14], accessible in all internet browsers (figure 15), in order to be friendly and easy used by all potential users.

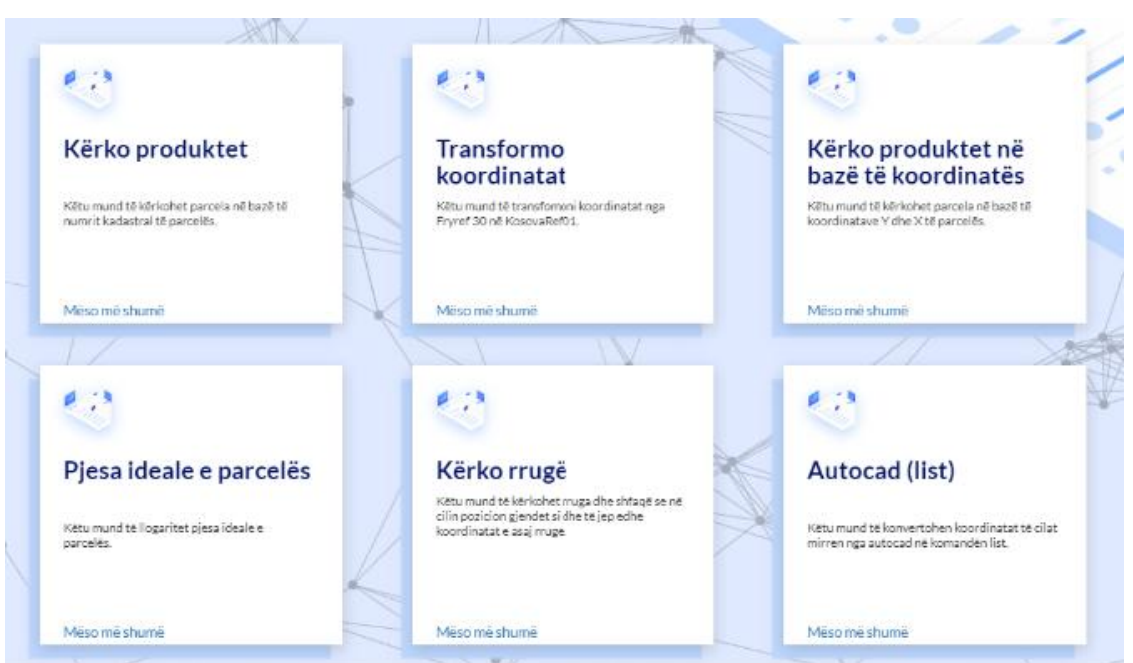

Figure 11. View of developed system via https://cadastral.ga/index.php

Interface is in national Albanian language, while its usage is limited just for commercial purposes based on registered official users. It contains 6 (six) modules: (1) Find products, (2) Transform coordinates, (3) Find product based on coordinates , (4) Ideal part of parcel, (5) Find road, (6) Autocad (list) 
First module of find products give opportunity to find parcel, select parcel (figure 15), report on cadastral unit (figure 16), overlapped view of vector data with google image as basemap, displaying vector data on urban developing plan and urban regulatory (figure 17).

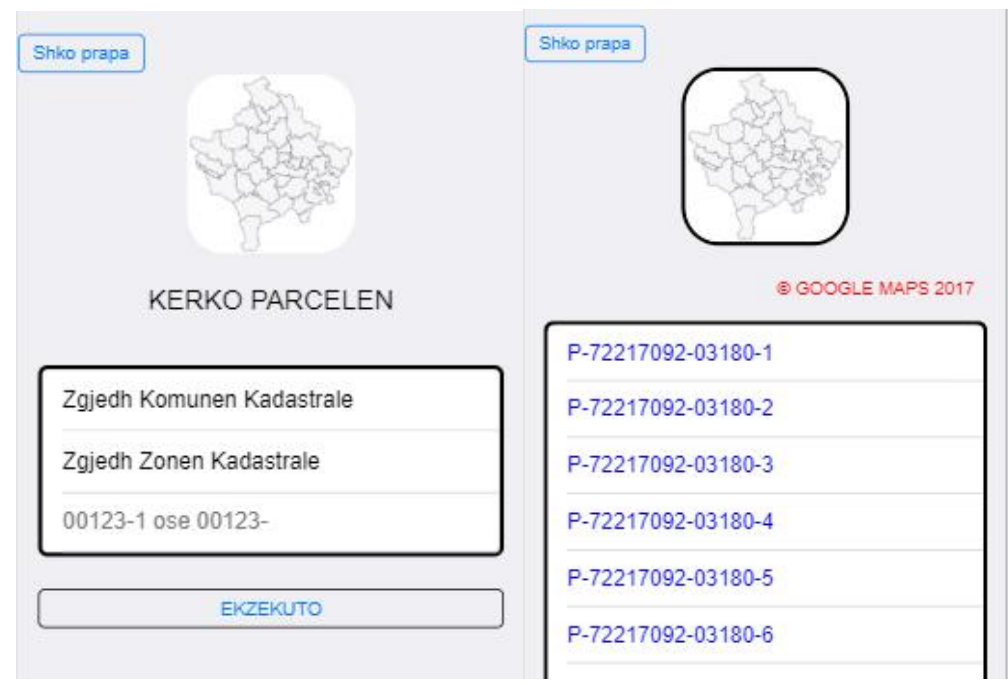

Figure 12. Find and select parcel

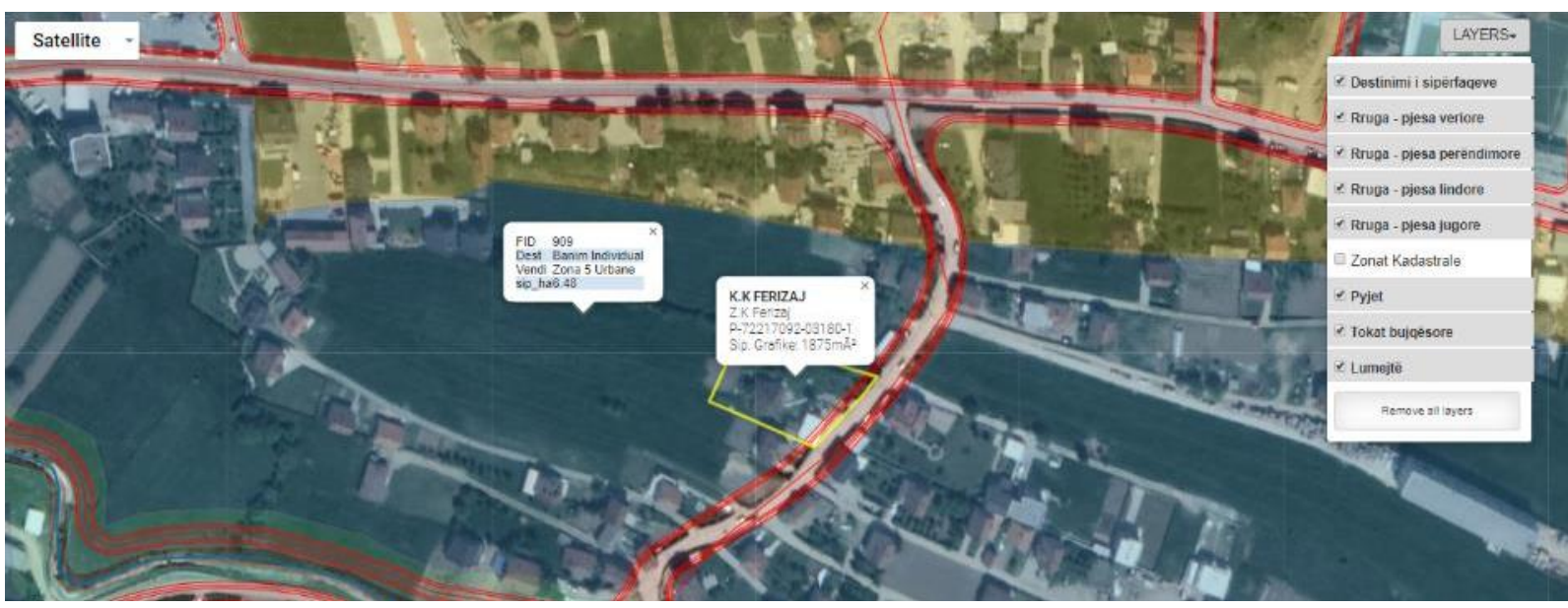

Figure 13. View on cadastral and urbanistic data with google satellite images 


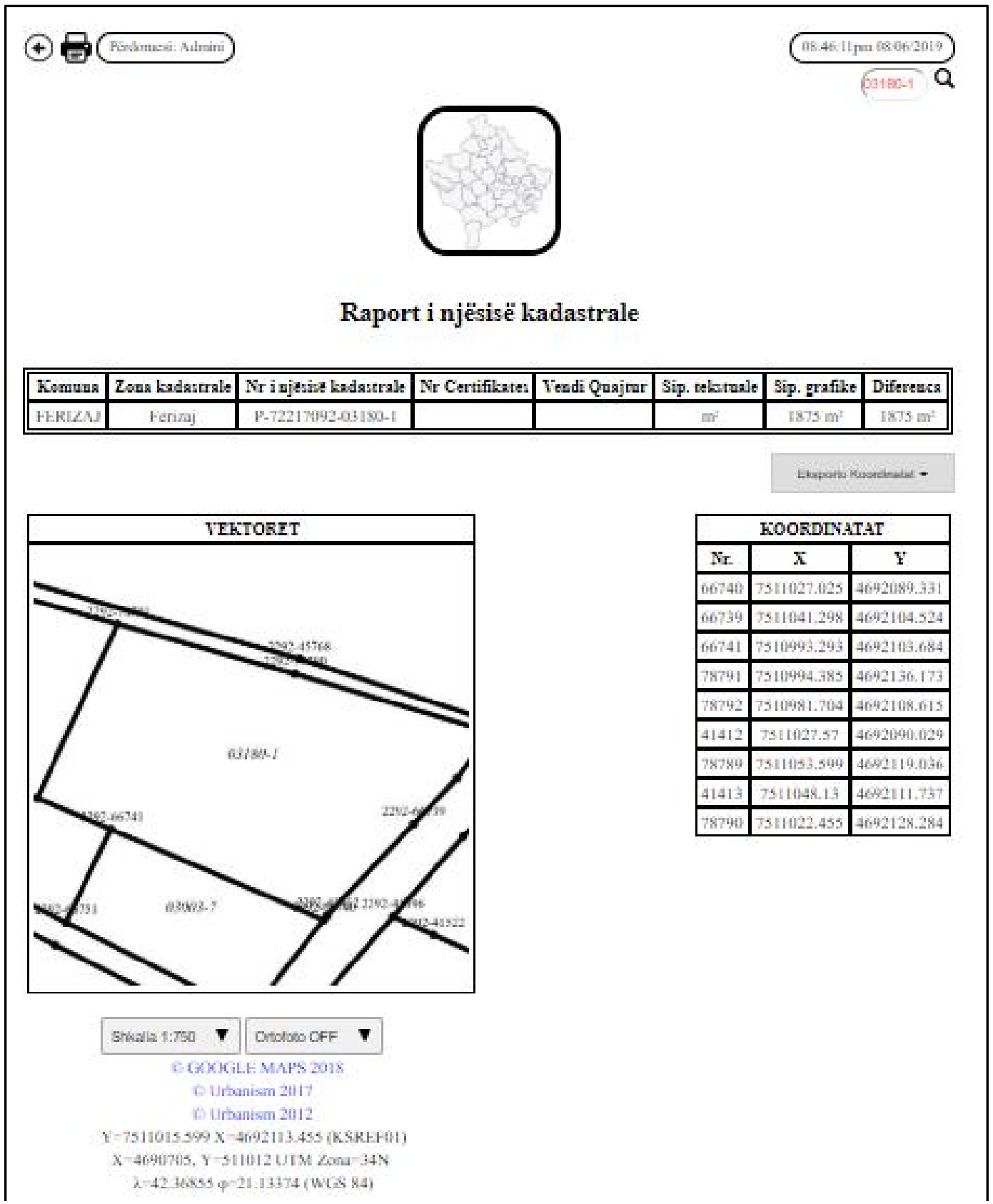

Figure 14. Report on cadastral unit

Second module allow coordinate transformation between CRSs Kosovaref01, UTM $34 \mathrm{~N}$ and WGS84, as vector/raster layers and as numerical values.

Third module provides function on search cadastral parcels based on the location defined with coordinates. It gives data for cadastral parcel based on location of point with defined coordinates, or list with information on cadastral zone, parcel number, area of polygon, and coordinates of boundary line, based on touch between polygon and point defined with coordinates (figure 15). 
In fourth module calculation of ideal part of parcel between two or more co-owners is enabled. Within this module two options are available: calculation of ideal part based on area and the opposite, and displaying calculated values.

Fifth module enable finding roads based on spatial location defined with coordinates and/or road name, as well displaying selected road with all attributes over the orthophoto image (figure 19).

Sixth module allows getting list with cartesian coordinates for all boundary points of cadastral parcels (figure 17).

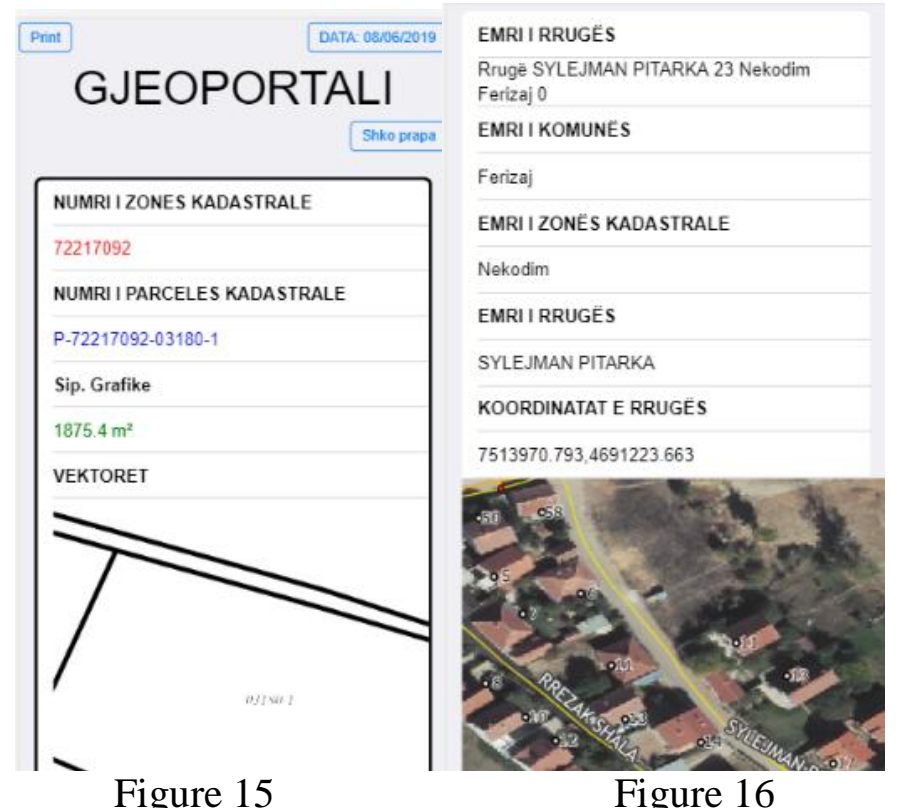

Figure $15 \quad$ Figure 16

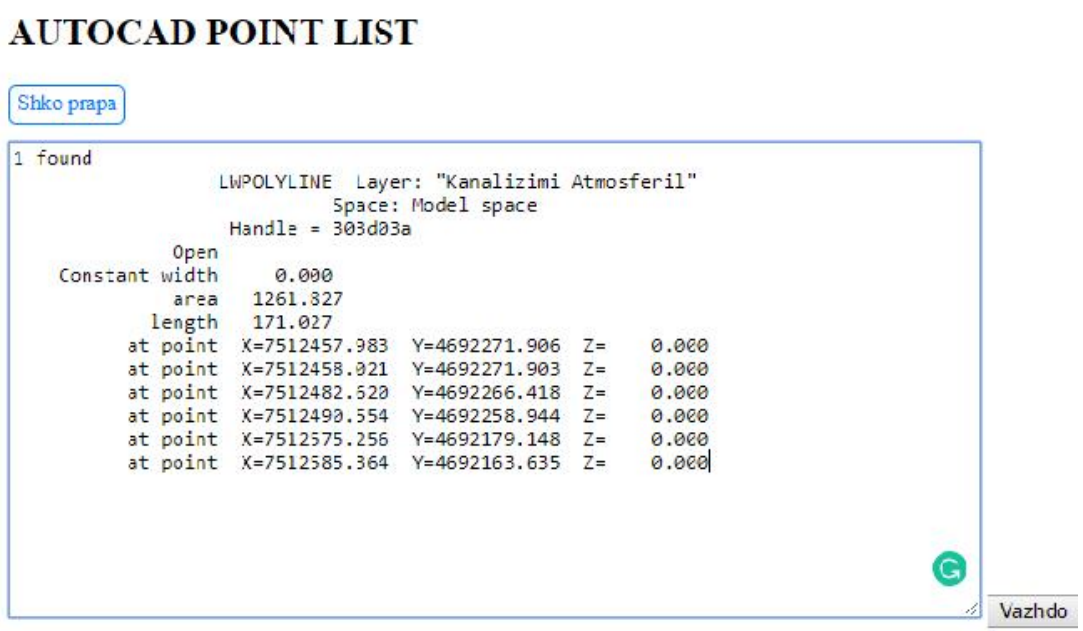

Figure 17. List of cartesian points

Main output from research project is web based online system with six modules (figure 15), that enable users to find provided products, transform coordinates between 
different CRSs', find products based on location/coordinates, divide parcels in ideal parts, find roads by attributes and obtain list of spatial coordinates in different coordinate systems.

Established platform includes dynamically many official geo databases coming from national cadastral database, national geoportal, different self-government sources, as well open layers. Platform doesn't have own database, due to usage of other geodata sources via web services, as well the methodology for establishing of SDI. Open geospatial consortium standards have been implemented in established platform.

Ferizaj municipality in the Republic of Kosova was case study area of performed research. In order to match main field activities of geo experts, especially in fields of cadaster, topographic surveying, and urban/spatial planning, platform is composed of six modules, with very simple interface in national Albanian language. Established platform is open and extendable. Based on user requirements, it is under permanent upgrading with new functionalities and links to new databases.

This system currently is in use by private surveying sector in the Republic of Kosova, started as pilot project in the area of Municipality of Ferizaj. Almost all cadastral offices which belongs to the cadastral unit of Ferizaj, are the subscriber of this system, and are using as basic platform for performing their activities in everyday work.

Usage of this platform is intending by developer to be used by all private surveying companies in Kosovo. Until now, this platform is well known and recognized in Kosovo by private surveying sector which are dealing with cadastral surveying, and the number of subscribers is increasing permanently about $17 \%$ per year.

Main advantage of this platform is dynamic based and extendable system, by giving opportunity to have in hand latest version of cadastral data coming by the national responsible institution KCA, and platform is open for extend with new functionalities based on users' feedbacks. Since KCA updates its cadastral database everyday between 4 and 5pm with changes happened within working day until 4pm, data available in this platform after $5 \mathrm{pm}$ is $100 \%$ same with the official cadastral database in KCA, while within working day from $8 \mathrm{am}$ to $4 \mathrm{pm}$ it has small differences only in a part of parcels that were subject of work in local cadastral offices. Joint usage of many databases, fast action, decrease cost and time consuming, and simple user interface as predefined objectives of new platform, were reached by developer and correctly recognized by users.

Spatial Data Infrastructure (SDI) encompasses policies, institutional framework, organizational guides, data, technologies, standards, delivery mechanisms, as well financial 
and human resources, to acquire, process, store, distribute, improve utilization, in order to increase access, availability, and sharing georeferenced spatial data, and to realize and foster services for citizens (Idrizi, 2009). Integrating of spatial data in to one unique standardized spatial data infrastructure, generate the simple and faster access to needed spatial data, more transparency, high level of cooperation between responsible state institutions, increasing the conscience for importance by spatial data, and much utilization of spatial data by all stake holders, clients and customers (Idrizi, 2018). Based on SDI technology, in next figure 1 the GIS cloud architecture which enables interlink between all GI actors.

Utilization of web services within SDI in order to support usage of geospatial information by geoclients, enables preconditions for establishing of e-business system within geo market. Commerce constitutes the exchange of products and services between businesses, groups and individuals and can be seen as one of the essential activities of any business. Electronic commerce focuses on the use of ICT to enable the external activities and relationships of the business with individuals, groups and other businesses or e-business refers to business with help of internet i.e. doing business with the help of internet network (Ferdousi and Al-Faisal 2018). A collaborative relationship between e-business and web GIS can manage huge data with the spatial reference which can be easily accessible to a different level of consumer, employee as well as government (Chaudhuri, 2015).

Geofencing is a technology when a mobile device enters or exits a predefined virtual geographic area and it generates a notification. It is one of the most popular Location Based Services (LBS). LBS is commonly used in Web GIS because this technology is for mobile clients and that's why it is more frequently used (Ferdousi and Al-Faisal 2018).

Beside data available in national geoportal, all institutions in Kosova own their spatial datasets according to their official responsibilities (https://www.rks-gov.net). Local selfgovernment develops three type of urbanistic plans, dedicated for spatial and urban planning of the municipal area, i.e. Municipal Developing Plans, Urban Developing Plans, and Urban Regulatory Plans (Idrizi et al, 2018), which are of big importance for everyday field work for surveyors in Kosova.

The findings of this study are related to some of the results of previous studies. Geospatial analysis could be used to overcome various kinds of problems in cities (Bryukhanova et al, 2018). Algorithm based applications are used in environmental related geospatial analysis (Nikolov et al, 2015). Automatic geodata services can meet the needs of a growing number of environmental data (Shi, 2015). Geo information and web technology can 
accommodate mathematical calculations for surveying purposes (Vorobev and Shakirova, 2016). Social aspects can be analyzed properly by using geoinformation (Glasze and Perkins, 2015)

The findings of this study have advantages compared to the results of the above studies. These advantages are this platform has positive impact on increasing geo market and extending geo business in Kosovo, which hastened practical act by surveying companies in performing cadastral and urbanistic works. Thus, it is very important platform for land administration and management system, real estate management, as well as sustainable economic development in geo sector and beyond. Nowadays it is in use by private geodetic sector, mainly for cadastral work, under managing of its developer, i.e. by second author of this paper. Official registering for usage is obligatory for all interested users, and chargeable.

\section{Conclusion}

In the absence of official application for online usage of spatial data, a voluntary platform for online and onsite usage of geoinformation coming from different databases. Platform is designed to be used through internet browsers, in order to be simple for usage, as well it is open for further extension with new modules and functionalities based on the user requirements. It is limited for usage only by subscribers, with time limited account, while there is not limit/levels for usage of modules by subscribers. Platform is well recognized in cadastral sector, mainly in area of Ferizaj municipality, since the pilot project was developed for this area. It is usable for entire area of Kosovo, because data used in system comes via national and local web servers (wms, wfs), as well open layers, without developing own databases.

\section{Conflict of Interest}

The authors declare that there is no conflict of interest with any financial organization regarding the material discussed in the article.

\section{References}

Alameh. N, (2010). Service chaining of interoperable Geographic Information Web Services. Global Science and Technology. Greenbelt, USA.

Brimicombe, A.J. (2002). GIS-where are the frontiers now. GIS 2002. Bahrain. 
Bryukhanova, E. A., Krupochkin, Y. P., \& Rygalova, M. V. (2018). Geoinformation technologies in the reconstruction of the social space of siberian cities at the turn of the 19-20th centuries (case study of the city of tobolsk). Journal of Siberian Federal University - Humanities and Social Sciences, 11(8), 1229-1242. doi:10.17516/19971370-0303

Chaudhuri, S. (2015). Application of Web Based Geographical Information Systems in ebusiness. Maldives.

Davis, C.A. and Alves L.L. (2007). Geospatial web services, Vicosa, Brazil.

ESRI. (2003). Spatial Data Standards and GIS interoperability. White paper. ESRI. CA. USA.

Ferdousi, . and Al-Faisal, A. (2018). Urban and regional planning. Rajshahi University of Engineering and Technology. Rajshahi. Bangladesh.

Gitis, V., Derendyaev, A., \& Weinstock, A. (2016). Web-based GIS technologies for monitoring and analysis of spatio-temporal processes. International Journal of Web Information Systems, 12(1), 102-124. doi:10.1108/IJWIS-10-2015-0032

Glasze, G., \& Perkins, C. (2015). Social and political dimensions of the OpenStreetMap project: Towards a critical geographical research agenda doi:10.1007/978-3-31914280-7_8

Henzen, C. (2018). Building a framework of usability patterns for web applications in spatial data infrastructures. ISPRS International Journal of Geo-Information, 7(11) doi:10.3390/ijgi7110446

Idrizi, B. (2009). Developing of National Spatial Data Infrastructure of Macedonia according to global standardization (GSDI and INSPIRE) and local status. Conference of Nikodinovski. Skopje. Macedonia.

Idrizi, B. (2018). General Conditions of Spatial Data Infrastructure. International Journal on Natural and Engineering Sciences. Turkey.

Idrizi, B. Sulejmani, V. Zimeri, Z. (2018). Multi-scale map for three levels of spatial planning data sets for the municipality of Vitia in Kosova. $7^{\text {th }}$ ICC\&GIS conference. Sozopol. Bulgaria.

Mwange, C., Mulaku, G. C., \& Siriba, D. N. (2018). Reviewing the status of national spatial data infrastructures in africa. Survey Review, 50(360), 191-200. doi:10.1080/00396265.2016.1259720 
Nikolov, B. P., Zharkikh, J. I., Soloviev, A. A., Krasnoperov, R. I., \& Agayan, S. M. (2015). Integration of data mining methods for earth science data analysis in GIS environment. Russian Journal of Earth Sciences, 15(4) doi:10.2205/2015ES000559

Sahin, K. and Gumusay, M.U. (2008). Service oriented architecture based web services for geographic information systems. The international archives of the remote sensing, photogrammetry and spatial information sciences. Vol XXXVII. Beijing. China.

Sayar, A. (2008). GIS service oriented architecture. Community grids laboratory. IN, USA.

Shi, S. (2015). Design and development of an online geoinformation service delivery of geospatial models in the united kingdom. Environmental Earth Sciences, 74(10), 70697080. doi:10.1007/s12665-015-4243-8

Siles, G., Charland, A., Voirin, Y., \& Bénié, G. B. (2019). Integration of landscape and structure indicators into a web-based geoinformation system for assessing wetlands status. Ecological Informatics, 52, 166-176. doi:10.1016/j.ecoinf.2019.05.011

Ummadi, P. (2008). Standards and Interoperability in GIS, Michigan State University. MI, USA.

Vorobev, A. V., \& Shakirova, G. R. (2016). Web-based geoinformation system for exploring geomagnetic field, its variations and anomalies doi:10.1007/978-3-319-29589-3_2

Walter, V., \& Sörgel, U. (2018). Implementation, results, and problems of paid crowd-based geospatial data collection. PFG - Journal of Photogrammetry, Remote Sensing and Geoinformation Science, 86(3-4), 187-197. doi:10.1007/s41064-018-0058-z 